\title{
LVI. On a theorem in plane kinetic trigonometry suggested by Gauss's theorem of Curvatura Integra
}

\section{Sir William Thomson}

To cite this article: Sir William Thomson (1891) LVI. On a theorem in plane kinetic trigonometry suggested by Gauss's theorem of Curvatura Integra , Philosophical Magazine, 32:198, 471-473, DOI: $10.1080 / 14786449108620210$

To link to this article: http://dx.doi.org/10.1080/14786449108620210

曲 Published online: 08 May 2009.

Submit your article to this journal $₫$

山 Article views: 2

Q View related articles ¿ 
take the trouble to look in the right places : for there cannot be any ground for the doubts cast upon the subject in the articles above quoted; seeing that the ignis fatnus is produced by the ignition either by lightning or by accidental flame of light carburetted hydrogen or marsh-gas which is generated by the decay of vegetable matter in boggy places; and the reason why the phenomenon is now so seldom seen is that these places have been drained and brought under cultivation.

Highgate, N., 4th Augnst, 1891.

LVI. On a Theorem in Plane Kinetic Trigonometry sugyested by Gauss's Theorem of Curvatura Integra. By Sir WILLIAM 'THOMson**.

1. A LBERT GIRARD'S beantiful theorem of the "SpheA rical Excess," in spherical trigonometry published about 1637 , and used practically 150 years later by General Roy in the trigonometrical survey of the British Isles, was splendidly extended by Gauss in his theorem ${ }^{\prime}$ of the "Curvatura Integra." There must be a corresponding theorem in the

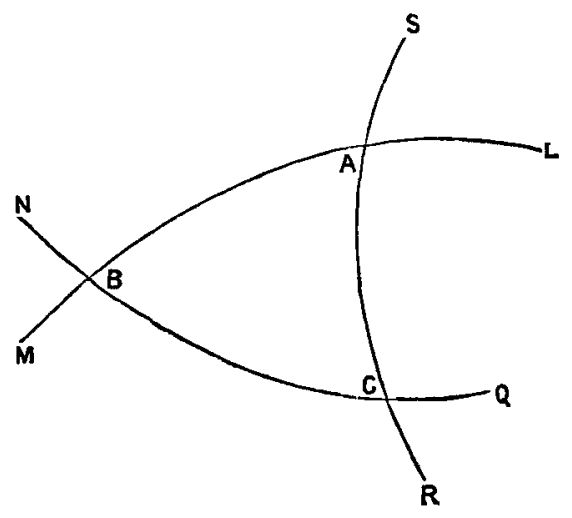

"kinetic trigonometry" suggested in the marginals of Thomson and Tait's ' Natural Philosophy,' $\$ \$ 3 \hat{1} 1(a)(b)(c)$ $(d)$, for the motion of the generalized conservative kinetic system of any number of variables. For the very simple cnse

* Communicated by the Author.

† "Disquisitiones Generales circa Superficies Curvas; auctore Carolo Frederico Gauss; Societati Regiæ [Gottingensi] Oblatæe n.virI. Octobr. mDccexxVII." Collected Works, Vol. IV, Göttingen 1873. Thomson and Tait's Natural Philosophy $\$ \$ 131$.... 138. 
of a material point moving in a plane it is easily worked out, as I have found in endeavouring to write a continuation of my article (Philosophical Magazine, October) on the Periodic Motion of a Finite System, which I hope may be ready to appear in the December number. Here is the theorem meantime.

2. Let LABM, NBCQ, RCA S be three paths of a particle moving freely in a plane, under influence of a force $\left(\frac{-d V}{d x}, \frac{-d V}{d y}\right)$ and projected from any three places in any direction in the plane, with such velocities that the sum of the kinetic and potential energies has the same value (E) in each case. The sum of the three angles A, B, C exceeds two right angles by an amount which, reckoned in radian, is equal to the surface-integral of $\nabla^{2} \log \sqrt{(\mathrm{E}-\mathrm{V})}$, throughout the enclosed area A B C; $\nabla^{2}$ denoting the Laplacian operation $\frac{d^{2}}{d x^{2}}+\frac{d^{2}}{d y^{2}}$.

3. To prove this ; remark that

$$
\iint d x d y \nabla^{2} \psi=\int d s \frac{d \psi}{d n},
$$

where $\psi$ denotes any function of $(x, y) ; \iint d x d y$ surfaceintegration throughout any area; $\int d s$ line-integration all round its boundary; and $\frac{d \psi}{d n}$ rate of variation of $\psi$ in the direction perpendicular to the boundary at any point. Hence the surface-integral mentioned in $\S 2$ is equal to

$$
\int d s \frac{-d \mathrm{~V}}{2(\mathrm{E}-\mathrm{V}) d n} \cdot \ldots . . .
$$

But $\frac{-d V}{d n}$ is the normal-component force ( $N$, we shall call it); and $2(\mathrm{E}-\mathrm{V})$ is the square of the velocity $\left(v^{2}\right.$, we shall call it). Hence (1) becomes

$$
\int d s \frac{\mathrm{N}}{v^{2}} \cdot \ldots \cdot \cdot \cdot \cdot \cdot .
$$

But $\mathrm{N} / v^{2}$ is the curvature $\left(\frac{1}{\rho}\right.$, we shall call it $)$, at any point in any one of the three $\operatorname{arcs}$ A B, B C, C A. Hence, dividing $\int d s$ into the three parts belonging respectively to these three 
arcs, which we shall denote by $\int_{\mathrm{A}}^{\mathrm{B}} d s, \int_{\mathrm{B}}^{\mathrm{C}} d s, \int_{\mathrm{C}}^{\mathrm{A}} d s$, we find for
$(2)$,

$$
\int_{\mathrm{A}}^{\mathrm{B}} \frac{d s}{\rho}+\int_{\mathrm{B}}^{\mathrm{C}} \frac{d s}{\rho}+\int_{\mathrm{C}}^{\mathrm{A}} \frac{d s}{\rho} \text {. . . . . }
$$

But $\int_{\mathrm{A}}^{\mathrm{B}} \frac{d s}{\rho}$ is the change of direction in the arc $\mathrm{AB}$, and similarly for the two others : hence the theorem.

LVII. On the Nature of Solution. By J. ALFred WANKLyN, W. JohNSTONE, and W. J. COOPER*

THE venerable Dalton made the great discovery, about the 1 year 1840, that contraction occurs when salts dissolve in water. In some instances the contraction is so great that the volume of the solution of the salt is not greater than that of the water itself-the contraction being as large as the volume of the anhydrous salt existing in the solution. Dalton experimented upon the same salt in its hydrated and in its anhydrous condition, and he also extended his investigation to a great variety of salts, and his results he sums up as follows $\dagger:-" I$ have tried the carbonates, the sulphates, the nitrates, the muriates or chlorides, the phosphates, the arseniates, the oxalates, the citrates, the tartrates, the acetates, \&c., \&c., and bave been uniformly successful : only the water adds to the bulk, and the solid matter adds to the weight."

Such was the condition in which Dalton left this subject about the year 1840 .

Taking up the investigation where Dalton left off, we find that in the majority of cases there is indeed considerable contraction when salts dissolve in water, but that the degree of contraction varies very widely with different salts. In some instances in which mineral matter dissolves in water, the contraction is so great that the volume of the solution is actually less than the volume of the water which forms it. This is strikingly exemplified by lime-water, which occupies less space than the water which it contains. On the other hand, there are cases where the volume of the solution of a mineral salt is almost as great as the sum of the volume of the salt plus the volume of the water in the solution. (The solution of nitrate of silver is a case in point.) There are even instances where expansion takes place. This is exemplified

* Communicated by the Authors.

† Henry's 'Life of Dalton' (Cavendish Society), p. 193. 